\title{
Gestão de pessoas por competências na administração pública: um estudo em São Mamede/PB
}

O estudo teve como objetivo investigar a forma de alocação por competências dos assistentes técnicos que integram o quadro funcional da gestão pública municipal de São Mamede/PB, buscando refletir acerca da importância da Gestão por Competências na esfera pública. A gestão de pessoas por competências é compreendida como um importante instrumento no contexto da gestão pública na busca por uma cultura de desenvolvimento contínuo e qualidade na prestação dos serviços ofertados a sociedade. Pelo exposto, buscando alcançar o objetivo traçado, a pesquisa utilizou-se da abordagem qualitativa, por meio de uma pesquisa descritiva, realizada através de um estudo de caso. Como instrumento de coleta de dados, foi utilizada a entrevista em profundidade com assistentes técnicos do quadro funcional da gestão pública municipal de São Mamede-PB, construída com base nas referências bibliográficas às quais estruturaram o presente trabalho. Com o resultado da pesquisa, foi possível constatar que os assistentes técnicos do órgão municipal estudado, atendem as exigências pertinentes às atribuições do cargo, embora a estratégia utilizada para realizar a distribuição destes servidores, durante os anos de serviços prestados, não observa as competências de cada um, pois não existe um processo de identificação destas. Outro fator essencial se refere à relação da Administração Pública Municipal com os agentes públicos que se restringe apenas a questões meramente burocráticas, desconsiderando a atuação da Gestão de Pessoas por Competências como ferramenta estratégica para o desenvolvimento do capital humano.

Palavras-chave: Administração Pública; Gestão por Competências; Servidor.

\section{Management of people by skills in public administration: a study in São Mamede/PB}

\begin{abstract}
The study aimed to investigate the form of allocation by competences of technical assistants who are part of the functional staff of the municipal public management of São Mamede/PB, seeking to reflect on the importance of Management by Competence in the public sphere. The management of people by competences is understood as an important instrument in the context of public management in the search for a culture of continuous development and quality in the provision of services offered to society. Therefore, seeking to achieve the objective outlined, the research used the qualitative approach, through a descriptive research, conducted through a case study. As a data collection tool, an in-depth interview with technical assistants of the São Mamede-PB municipal public management staff was used, built based on the bibliographic references to which they structured the present work. With the result of the research, it was possible to verify that the technical assistants of the studied municipal agency, meet the requirements pertinent to the attributions of the position, although the strategy used to accomplish the distribution of these servants, during the years of services rendered, does not observe the competences of each one, because there is not a process of identification of these competences. Another essential factor refers to the relationship between the Municipal Public Administration and public agents that is restricted only to purely bureaucratic issues, disregarding the performance of People by Competence Management as a strategic tool for the development of human capital.
\end{abstract}

Keywords: Public Administration; Management by competence; Server.

Topic: Gestão Pública

Reviewed anonymously in the process of blind peer.

Carolinne Carvalho de Araújo (iD

Universidade Estadual da Paraíba, Brasil

http://lattes.cnpq.br/4442318631520805

http://orcid.org/0000-0002-5555-4321

carolinecarvaraujo@gmail.com

Cinthia Moura Frade (D)

Universidade Estadual da Paraíba, Brasil http://lattes.cnpq.br/5264348035661218 http://orcid.org/0000-0002-2826-816X

admcinthiafrade@gmail.com

Lucas Andrade de Morais (it)

Universidade Estadual da Paraíba, Brasil

http://lattes.cnpq.br/4304836710800316

http://orcid.org/0000-0003-4443-2393

lucasmorais7@gmail.com

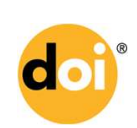

DOI: 10.6008/CBPC2179-684X.2020.004.0013
Received: 07/10/2020

Approved: 21/12/2020

\author{
Mariana Ferreira Pessoa (iD \\ Universidade Federal da Paraíba, Brasil \\ http://lattes.cnpq.br/7235954275825642 \\ http://orcid.org/0000-0002-1563-5469 \\ marianafepessoa@gmail.com \\ Aline Medeiros de Sousa \\ Instituto Federal da Paraíba, Brasil \\ http://lattes.cnpq.br/9143667868471303 \\ http://orcid.org/0000-0001-8797-7575 \\ alinesousa73@hotmail.com
}

Referencing this:

ARAÚJO, C. C.; FRADE, C. M.; MORAIS, L. A.; PESSOA, M. F.; SOUSA, A. M.. Gestão de pessoas por competências na administração pública: um estudo em São Mamede/PB. Revista Brasileira de Administração Científica, v.11, n.4, p.166-177, 2020. DOI:

http://doi.org/10.6008/CBPC2179-684X.2020.004.0013 


\section{INTRODUÇÃO}

A Administração Pública, regulamentada por princípios constitucionais da legalidade, impessoalidade, moralidade, publicidade e eficiência (Art. 37, CF/88), tem por objetivo atender aos interesses da coletividade e às necessidades sociais em todas as suas instâncias, utilizando-se de estruturas administrativas, direta ou indiretamente, assim como por meio de formas legalmente permitidas.

Na Gestão Pública, a administração não está restritamente voltada para a prestação de serviços, mas trata-se também de gerir visando à satisfação e o bem-estar do coletivo e, para isto, é preciso que todo arranjo administrativo esteja em concordância e em constante equilíbrio, para cumprir os ditames legais, além de atender de forma eficiente, eficaz e efetiva, as demandas existentes. Para que isso ocorra de forma apropriada, é fundamental que a administração pública seja constituída por agentes públicos qualificados, que disponham de competências técnicas, humanas e gerencias de forma integrada.

Nessa perspectiva, a gestão de pessoas no setor público tem um papel estratégico com o intuito de gerar resultados positivos atendendo aos objetivos organizacionais das gestões públicas. No entanto, segundo Gemelli et al. (2010), percebe-se que há uma grande distância entre a forma que se compõe o quadro funcional do setor de recursos humanos na esfera pública e o que se precisa ter. Desse modo, além do conhecimento, é necessária qualificação para que cada servidor exerça sua função com propriedade, utilizando os recursos de forma racional e devida.

De acordo com a Organização para a Cooperação e o Desenvolvimento Econômico - OCDE (2010), os resultados finais das atividades públicas ao final do dia são provenientes dos esforços e do empenho dos servidores para com a gestão pública. Deste modo, é possível compreender as principais preocupações dos governos, que estão atreladas ao desempenho, eficiência e eficácia dos agentes públicos. Portanto, são necessárias práticas apropriadas de gestão de recursos humanos, uma vez que são fundamentais para uma alta performance.

A Gestão por Competências no contexto público é um debate que envolve aspectos importantes que podem trazer melhorias internas e externas para os órgãos. Os conteúdos de abordagem acerca dessa problemática são restritos, o que por vezes dificulta uma análise mais aprofundada. Segundo a OCDE (2010), as práticas de gestão de recursos humanos no governo federal tendem a estar mais voltadas para o simples controle do cumprimento de regras e normas básicas, havendo um mínimo espaço para a gestão estratégica baseada em desempenho e competências.

Diante disso, o presente trabalho visa responder a seguinte problemática: Como se dá a alocação por competências dos assistentes técnicos na gestão pública municipal de São Mamede - PB? Frente ao contexto apresentado, o objetivo geral da pesquisa consiste em investigar a forma de alocação por competências dos assistentes técnicos que integram o quadro funcional da gestão pública municipal de São Mamede - PB. Em conformidade com o objetivo geral estabelecido, foram definidos os seguintes objetivos específicos: (a) Discutir e refletir acerca da importância da Gestão por Competências como ferramenta que auxilia o alcance dos objetivos no atual sistema de gestão pública; (b) Observar as competências, considerando os 
conhecimentos, as habilidades e as atitudes dos assistentes técnicos que atuam na Prefeitura Municipal de São Mamede - PB; (c) Avaliar como ocorre a distribuição das atividades profissionais dos assistentes técnicos da Prefeitura Municipal de São Mamede - PB.

No que se concerne à estruturação da pesquisa, consiste em cinco capítulos. O primeiro trata-se da presente introdução; o segundo é referente à discussão teórica sobre Gestão por Competências no setor público; o terceiro apresentou os procedimentos metodológicos para alcançar os objetivos traçados e a problemática da pesquisa delineada, o quarto é sobre as discussões dos resultados e, por fim, o quinto capítulo esboçou as considerações finais do estudo.

\section{REVISÃO TEÓRICA}

\section{Gestão por competências no setor público}

A administração pública vem evoluindo e se consolidado como objeto de consideráveis pesquisas, dada a quantidade de literatura publicada sobre o tema (SMOLSKI et al., 2017). Segundo Branchier et al. (2007), a administração pública se caracteriza como a gestão de bens e interesses da comunidade em geral nas esferas federais, estaduais e municipais, conforme os princípios do Direito e da Moral, objetivando o bem-estar comum. Quanto à definição de órgãos públicos, se tratam de centros de competências criados para o desenvolvimento de funções estatais, por meio de agentes, em que a atuação é responsabilizada à pessoa jurídica a que pertencem. Enquanto que os agentes públicos são todas as pessoas físicas encarregadas, definitiva ou temporariamente, do exercício de alguma função estatal.

Quanto à formação de um órgão público, a Constituição Federal, conforme descrito no artigo 37, regulamenta que os empregos e funções públicas são acessíveis aos brasileiros e aos estrangeiros que preencham os requisitos estabelecidos em lei, podendo ocupar cargos efetivos provenientes de concursos públicos ou cargos temporários, como casos de contratações por tempo determinado para atender necessidades de excepcional interesse público e cargos de comissão declarados através de nomeações.

Partindo dessa contextualização, Brandão et al. (2009) salientam que diante dos processos de transformação sociais, econômicas, políticas e culturais, faz-se necessário um processo de reestruturação produtiva. Como resposta a esse impacto de reestruturação em que o desafio das organizações está voltado para o desenvolvimento e utilização de mecanismos de gestão que lhes garantam certa aptidão e vantagem competitiva, as propostas para tal obtenção caminham em uma mesma direção: gestão estratégica de pessoas (BRANCHIER et al., 2007).

Nesse entendimento, Brandão et al. (2009) apresentam que as gestões por competências, assim como a gestão por desempenho, podem ser visualizadas como instrumentos que englobam um mesmo movimento, direcionado a proporcionar alternativas eficientes de gestão para as organizações.

No que se refere à funcionalidade das entidades públicas, na compreensão de Gemelli et al. (2010), a sociedade tem expectativas distintas acerca da gestão pública e atender tais expectativas necessita de capacidade para mapear e gerenciar tanto os conhecimentos organizacionais quanto as competências. 
Todavia, ainda segundo estes autores, torna-se necessário perceber as características inerentes à gestão de pessoas no segmento público, uma vez que está requer cumprimento, na sua formulação, desenvolvimento e implantação às exigências legais, do exercício absoluto da cidadania e aos princípios de igualdade de acesso e continuidade à prestação dos serviços públicos.

A fim de incentivar transformações em alguns traços peculiares associados à organização de pessoas do serviço público, é válido mencionar a publicação do Decreto no 5.707 de 23 de Fevereiro de 2006, que trata dos temas da gestão por competências e da avaliação de desempenho, respectivamente, instituindo políticas e diretrizes para o desenvolvimento de pessoal da Administração Pública federal apontando que a gestão por competência trata-se da "gestão da capacitação orientada para o desenvolvimento do conjunto de conhecimentos, habilidades e atitudes necessárias ao desempenho das funções dos servidores, visando ao alcance dos objetivos da instituição".

Ainda que com limitações, o Decreto 5.707/2006 tomou como premissa a adequação entre as competências requeridas dos servidores e as necessárias ao alcance dos objetivos e resultados pretendidos pelas instituições, porém este Decreto acabou sendo revogado, dando espaço para o Decreto 9.991/2019 que trouxe alterações em vários sentidos e principalmente no que diz respeito a Gestão por Competências, trazendo agora um conceito importante que retrata sobre as competências transversais, que são habilidades requeridas por todos os servidores, independentemente de sua unidade setorial ou instituição ao qual presta seus serviços.

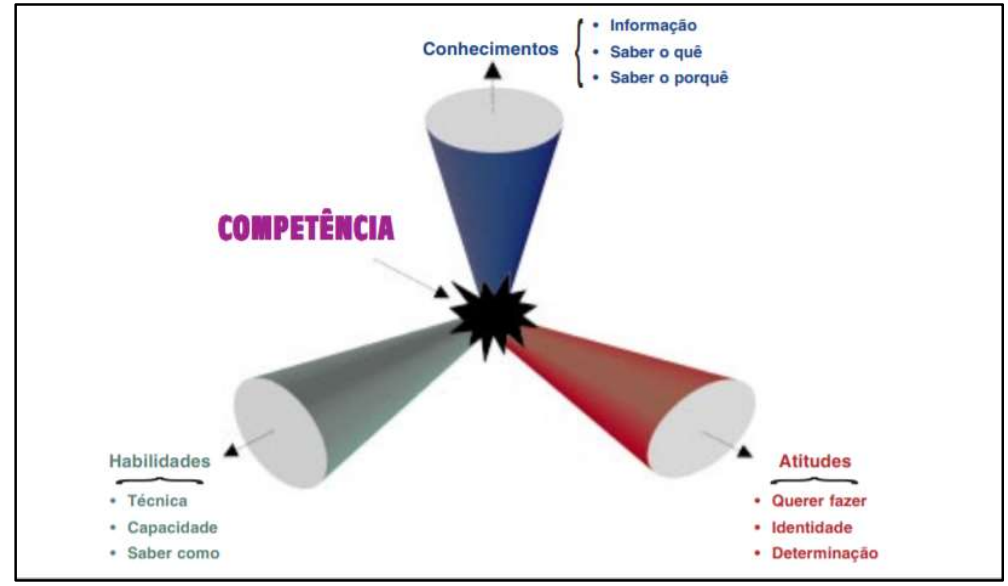

Figura 1: As três dimensões da competência. Fonte: Brandão et al. (2009).

Segundo Brandão et al. (2001), as competências, de um modo geral, dizem respeito a um conjunto que engloba conhecimento, habilidades e atitudes (CHA), sendo esses aspectos apontados na Figura 1, considerados necessários para a execução de uma determinada atividade.

Para Brandão et al. (2008), a gestão do desempenho humano no ambiente de trabalho sempre constituiu assunto polêmico nas organizações. "As distorções e a subjetividade inerentes a muitos instrumentos de avaliação do desempenho contrapõem-se às necessidades de mensuração de resultados, levando a conflitos" (BRANDÃO et al., 2008).

Neste contexto, é possível perceber que existem algumas barreiras ao gerir perfis de funcionários públicos, o que impossibilita a percepção de pontos de excelência e melhoria para se alcançar o objetivo 
central. Com isso, a elaboração de estratégias a fim de fortalecer a prestação do serviço se faz necessária, tendo em vista que cada órgão público tem o compromisso de "avaliar, validar e fazer evoluir as competências de seus servidores" (AMARAL, 2006).

De acordo com a Organização para a Cooperação e o Desenvolvimento Econômico (2010), a gestão por competência está sendo abordada inicialmente com o intuito de reforçar e redirecionar a constituição e o avanço para engrandecer o serviço público e expandir uma cultura de desenvolvimento contínuo. De modo que, os governos precisam aperfeiçoar a capacidade, a eficiência e a competência das administrações e serviços públicos. Por isso, os esforços para alcançar estas questões levantam muitos quesitos, incluindo o regimento da administração pública, a maneira de orçar e a utilização de tecnologias de informação.

Bresser-Pereira (2002) garante que é necessário dar mais autonomia aos agentes públicos, uma vez que diante da competição cada vez mais forte presente no sistema capitalista, as restrições econômicas ou de eficiência de uma reforma da gestão pública por meio de servidores mais capacitados, bem como as agências/órgão gerenciadas pelos mesmos se tornem mais autônomas administrativamente e mais transparentes politicamente.

Neste contexto, "não há competência senão posta em ato, a competência só pode ser competência em situação" (LE BOTERF, 2003), ou seja, para que se possa atribuir competências a um determinado indivíduo, é necessário observá-lo em situação de trabalho, não sendo suficiente apenas seus conhecimentos acerca da temática da situação, é fundamental também que o indivíduo saiba colocar este conhecimento em prática.

Na perspectiva de Capuano (2015), a nova ética de competências para a gestão de pessoas requer uma reflexão sobre o atual modelo de recrutamento e seleção de pessoas para as carreiras no contexto público.

O modelo vigente, baseado no instituto do concurso público, permite apenas a avaliação de conhecimentos e a valoração de títulos acadêmicos, ignorando qualquer habilidade e perfil comportamental do candidato, salvo as exceções de praxe (como nos casos das carreiras policiais em geral e de alguns cargos com funções operacionais manuais, como o de gari). (CAPUANO, 2015)

Sendo, então, fundamental que o governo federal comece a observar o recrutamento de pessoal além de testes de habilidades acadêmicas e conhecimentos básicos, principalmente para os cargos que requerem qualificações específicas. Baseado em tal afirmação, "a introdução de métodos de recrutamento modernos significa focar na mensuração de competências e experiências anteriores, sem prejudicar a transparência e o mérito" (OCDE, 2010).

\section{METODOLOGIA}

O estudo realizado é norteado por uma abordagem qualitativa para perscrutar como são alocados os servidores públicos municipais de São Mamede - PB, levando em consideração as competências que eles possuem. Segundo Flick (2009), esse tipo de abordagem compreende a "escolha adequada de métodos e teorias convenientes; no reconhecimento e na análise de diferentes perspectivas; nas reflexões dos pesquisadores a respeito de suas pesquisas como parte do processo de produção de conhecimento; e na 
variedade de abordagens e métodos".

Diante do objeto de estudo, esta pesquisa está balizada na perspectiva descritiva que, em conformidade com Zanella (2009), pretende, através dos significados que o ambiente demonstra, descrever os fenômenos, portanto, os resultados obtidos são definidos na forma de entrevistas, declarações, narrativas, estudos de campo, entre outros meios. Destarte, o campo de análise da pesquisa foi a Gestão Pública municipal de São Mamede e os sujeitos de pesquisas os assistentes técnicos que compõem o quadro funcional do órgão.

A cidade de São Mamede - PB está localizada geograficamente na Mesorregião do Sertão Paraibano. De acordo com o Instituto Brasileiro de Geografia e Estatística (IBGE, 2019), a população da cidade, segundo o censo de 2019, está estimada em 7.724 pessoas. Conforme o site da Prefeitura Municipal de São Mamede$\mathrm{PB}$, por muitos anos a atividade industrial foi um marco na economia da cidade, impulsionada por uma usina de algodão, que chegava a representar $80 \%$ do PIB local, no entanto, houve uma queda significativa da produção de algodão com o passar dos anos. Atualmente, ainda de acordo com o site da Prefeitura Municipal, a economia da cidade é caracterizada pelo comércio, como a existência de mercados, farmácias e lojas convencionais, pela atividade agrícola e pelo funcionalismo público, principalmente dos âmbitos municipais e estaduais.

Quanto aos servidores públicos da Prefeitura Municipal de São Mamede - PB, de acordo com informações repassadas pela Chefia de Gabinete, a formação do quadro de pessoal se compõe da seguinte forma descrita na tabela 1.

Tabela 1: Quadro Funcional da Prefeitura Municipal de São Mamede - PB.

\begin{tabular}{l|lllll}
\hline Unidade de Lotação & Comissionado & Contratado & Efetivo & Eletivo & Geral \\
\hline Gabinete do Prefeito & 6 & - & 3 & 1 & 10 \\
Procuradoria Geral & 3 & - & - & - & 3 \\
Sec. de Administração & 5 & - & 6 & - & 11 \\
Sec. de Agricultura e Desenvolvimento Rural & 2 & - & 1 & - & 3 \\
Sec. de Desenvolvimento Social e Humano & 5 & - & 7 & - & 12 \\
Sec. de Educação & 16 & - & 194 & - & 210 \\
Sec. de Esporte e Lazer & 2 & - & - & - & 2 \\
Sec. de Finanças e Planejamento & 3 & - & - & 6 \\
Sec. de Infraestrutura & 6 & - & - & 35 \\
Sec. De Saúde & 24 & 5 & 56 & - & 85 \\
Sec. De Turismo e Meio Ambiente & 1 & - & - & - & 1 \\
TOTAL & 73 & 5 & 299 & 1 & 378 \\
\hline
\end{tabular}

Utilizamos como técnica a entrevista em profundidade, em que o roteiro de questões desta foi realizado com base na fundamentação teórica discutida no trabalho. Enquanto técnica de coleta de dados, "a entrevista é bastante adequada para a obtenção de informações acerca do que as pessoas sabem, creem, esperam, sentem ou desejam, pretendem fazer, fazem ou fizeram, bem como acerca das suas explicações ou razões a respeito das coisas precedentes" (SELLTIZ et al., 1967). A entrevista em profundidade, portanto, possibilitou a obtenção de informações qualitativas, coletando os sentimentos dos entrevistados no que diz respeito a determinadas questões (PERDIGÃO et al., 2012).

Com o roteiro de entrevista definido, no dia 09 de outubro de 2018 foi realizada uma visita à Chefia de Gabinete da Prefeitura Municipal de São Mamede - PB, a fim de coletar informações acerca do 
quantitativo de assistentes técnicos que integram o quadro funcional do órgão, bem como suas respectivas lotações. Após obter as informações solicitadas, foi possível identificar cinco sujeitos para a pesquisa. No entanto, devido dois agentes estarem afastados das suas atribuições por motivos de vacância e licença, a entrevista foi realizada com três servidores.

Para minimizar possíveis distorções da realidade, suavização ou exageros dos fatos correlacionados a probabilidade de preocupação por parte dos entrevistados da exposição dos seus nomes, a pesquisa manteve o anonimato dos sujeitos, os quais foram submetidos às entrevistas, visando o conhecimento sobre suas percepções quanto ao objeto estudado.

Pelo exposto, o procedimento de análise de dados adotado foi a análise temática e interpretativa proposta por Severino (2018), permitindo, assim esboçar os objetivos delineados e responder ao problema de pesquisa estabelecido para o presente estudo.

\section{RESULTADOS E DISCUSSÃO}

A análise dos dados colhidos exposta nesta seção levou em consideração a fundamentação teórica a qual se iniciou a pesquisa, observando os conceitos abordados, contrapondo com as percepções dos três servidores entrevistados. O perfil dos sujeitos tem como características: possuem mais de 41 anos de idade, estão ingressos no serviço público há mais de 15 anos e todos os sujeitos possuem formação superior sendo o Entrevistado 1 formado em Ciências da Computação, o Entrevistado 2 em Agronomia e o Entrevistado 3 possui o curso superior de Licenciatura Plena em Geografia.

Quanto à formação acadêmica dos servidores entrevistados e sua relação com a função exercida na Prefeitura Municipal de São Mamede - PB, o Entrevistado 3 revelou que seu curso superior nada tem vinculação com suas atividades produzidas, enquanto os entrevistados 1 e 2, apontaram que suas formações, apesar não possuírem uma associação considerável ao cargo nomeado através do concurso público, possuem correspondência com as funções que são desempenhadas por eles atualmente.

Quando questionados acerca das atribuições de um assistente técnico, o Entrevistado 2 afirma ter um conhecimento claro sobre as competências técnicas do cargo, uma vez que ao se submeter ao concurso público, essas questões já podem ser observadas no edital do concurso. O Entrevistado 2, em consonância com o discurso do Entrevistado 3, ainda relata que no órgão municipal não há essa definição clara sobre as incumbências inerentes a alguns cargos, completando que fica a cargo do próprio servidor público procurar se atualizar e estar ciente de tais informações.

Contrapondo a referida informação, o Entrevistado 1 afirma existir sim uma definição formalizada acerca das funções determinadas a um assistente técnico. Ainda segundo ele, há uma documentação demonstrando o que deve ser feito e exercido durante o período que um assistente técnico estiver trabalhando no serviço público municipal, ressaltando que existe um protocolo a ser seguido para cada função. A fim de esclarecer esta questão, de acordo com informaç̧̃es obtidas por meio da Chefia de Gabinete da Prefeitura Municipal, existe de fato um documento institucional em que são definidas as responsabilidades do cargo de assistente técnico. 
Para o próximo questionamento foi tomado como base o conjunto de conhecimentos, habilidades e atitudes instituído no Decreto № 5.707, de 23 de Fevereiro de 2006 e atualizadas no Decreto 9.991/2019 que revogou este primeiro, como aspectos necessários ao desempenho das funções de um servidor e, ainda considerando essas três dimensões relacionadas ao trabalho, atrelado a isso, vale destacar as premissas de Brandão et al. (2009) afirmando que:

Tais dimensões são interdependentes na medida em que, para a exposição de uma habilidade, se presume que o indivíduo conheça princípios e técnicas específicos. Da mesma forma, a adoção de um comportamento no trabalho exige da pessoa, não raras vezes, a detenção não apenas de conhecimentos, mas também de habilidades e atitudes apropriadas. (BRANDÃO et al., 2009)

Com isso, observando o conhecimento como 'saber', as habilidades como o 'saber fazer' e os aspectos comportamentais como o 'querer fazer', foi questionado aos três entrevistados quais conhecimentos técnicos, quais habilidades e quais atitudes são necessárias ao assistente técnico para desempenhar suas atividades de forma competente e, de um modo geral, os entrevistados julgaram ser fundamentais os seguintes aspectos: De conhecimento teórico, o Entrevistado 1 afirma ser fundamental possuir uma compreensão de assuntos relacionados ao Ensino Médio; o Entrevistado 2 relatou ser necessário conhecer algumas leis, normas e diretrizes e manter-se atualizado sobre elas, uma vez que estão em constantes mudanças, enquanto o Entrevistado 3, em um discurso raso, julga ser preciso saber organizar e separar documentos institucionais.

No que tange as habilidades, os três entrevistados apontam agilidade e organização como pontos importantes. O Entrevistado 2 ainda acrescenta que é fundamental saber fazer alguns documentos que são muito utilizados no serviço público, como ofícios e memorandos. Somando a essa ideia, o Entrevistado 3 destaca que conhecer ferramentas básicas de informática também é essencial.

Na terceira dimensão, alusiva as atitudes, em concordância, os três servidores salientam que é de extrema importância prestar um serviço com qualidade ao indivíduo que os procuram, realizando um atendimento pontual e buscando a solução adequada. Nesse entendimento, o Entrevistado 2 quando questionado, coloca algo relevante e em sua fala ressalta:

É necessário se doar no trabalho para que a função seja exercida de uma maneira que possa atender as exigências da sociedade, promovendo um trabalho não refletido basicamente em si, mas pensando na sociedade que está pagando os servidores públicos através de impostos e por isso é necessário estar preparado para atendê-los no momento certo, promovendo qualidade de vida a quem precisa (E2).

Como sequência, a partir das indagações realizadas, foi proposto aos três entrevistados realizar uma autoanálise acerca de quais dessas competências apontadas eles possuem, quais não possuem e quais possuem, mas consideram que é necessário melhorar. Nesse quesito, houve uma clara barreira cultural quanto à dificuldade de se auto avaliar, em que os três entrevistados caminharam para um mesmo direcionamento de resposta, conforme fala do Entrevistado 1: "Essa questão deveria ser feita a quem estar recebendo o serviço, ou seja, as pessoas de fora podem responder melhor" (E1).

Quando indagados sobre o aproveitamento e aceitação de suas competências individuais ao assumirem o concurso público e frente às diferentes gestões que passaram pelo órgão municipal, o 
Entrevistado 1 relatou que embora estivesse assumindo um cargo administrativo, foi direcionado ao setor da Educação para desempenhar funções de ensino esportivo junto a crianças, em que expôs se identificar com as atividades desempenhadas na época. Atualmente, executa funções pertinentes à pasta de Secretário de Administração.

O Entrevistado 2 relata que já trabalhava na prefeitura antes mesmo de inscrever-se para o concurso, e com o lançamento do concurso público municipal, procurou somente se efetivar. Este expôs ainda que realizou as avaliações para agente administrativo por não ter cargo relacionado ao seu curso, ligado à Agronomia, no entanto, seu conhecimento de Engenheiro Agrônomo sempre foi aproveitado.

Já o Entrevistado 3 aponta que não foram aproveitados conhecimentos relacionados ao seu curso superior, mas suas habilidades individuais foram bem aceitas e lhes ajudaram a desempenhar suas funções. Quanto ao relato deste servidor, vale aferir que suas atribuições e experiências profissionais, por significativos anos, estiveram atreladas ao departamento de pessoal, e que a cerca de dois anos o Entrevistado 3 foi remanejado de setor, mas, devido sua vasta experiência, continua dando suporte, quando necessário, ao setor de RH Municipal.

Como observado na discussão teórica, a OCDE (2010) ressalta ser necessário que os órgãos públicos analisem o recrutamento de pessoal além das habilidades acadêmicas, fundamentalmente a cargos que requerem uma qualificação intrínseca. Nesse âmbito, é possível perceber uma deficiência por parte da Gestão Pública em identificar cargos necessários ao funcionalismo público, impossibilitando que os indivíduos se inscrevam para cargos que correspondam as suas formações, considerando também a utilidade de determinadas funções à instituição pública.

Consoante Branchier et al. (2007) em que a Administração Pública objetiva promover o bem-estar comum, por meio de agentes públicos desempenhando funções em órgãos públicos, foi questionado aos entrevistados se as funções exercidas colaboram para que a gestão pública municipal alcance seus objetivos, a fim de identificar se os servidores entrevistados têm ciência do seu papel no processo de contribuição para o alcance das metas estabelecidas.

Neste quesito, o Entrevistado 2 coloca uma questão significativa, já que este considera ser um ponto que apresenta certa dificuldade, apontando que o trabalho que lhes compete é feito, mas a gestão tem seus programas que, por vezes, não é do acompanhamento, nem do conhecimento dos servidores. 0 entrevistado afirma fazer sua parte, assim como espera que a gestão faça a sua e considera estar dando tudo certo, pois até o presente momento não Ihes foi cobrado nada além do que já vem sendo feito. Já o Entrevistado 3 relata que sempre trabalhou com ética profissional, sabendo ouvir e falar no momento certo, de forma respeitosa, e que isso é fundamental para geração de um bom serviço.

Considerando que, "os servidores precisam ser habilitados a prestar um bom serviço e a reforçar as suas próprias capacidades e competências" (OCDE, 2010), quando questionados acerca da participação dos entrevistados em capacitações e qualificações promovidas pelo órgão municipal, os servidores afirmam já terem recebido esse tipo de incentivo e que as melhorias após esses treinamentos são perceptíveis e consideráveis. 
De início, devido à época e observando que as coisas não eram tão atualizadas como hoje, não havia muitas reuniões, mas com o passar dos anos, algumas reuniões, assessorias, capacitações, passaram a ser mais frequentes. Como ultimamente, com essa nova gestão, teve uma capacitação e foi riquíssima. Quanto mais adquirimos conhecimento, melhor (E3).

[...] temos também a oportunidade de lidar com outras pessoas, outras comunidades, realizar trocas de conhecimento, então tudo isso favorece nossa atividade do dia a dia. $\mathrm{O}$ conhecimento não tem limite, cada vez mais é possível aprender algo novo que pode servir para nosso o desempenho do dia a dia como cidadão que trabalha para a coletividade (E2).

Observando a Gestão de Recursos Humanos dentro dos órgãos públicos como algo restrito a fiscalização do cumprimento de regimentos, como aponta o OCDE (2010), quando indagados acerca da comunicação entre a Administração de Pessoal e o servidor público de modo geral, os entrevistados 2 e 3 , afirmaram que essa relação se restringe apenas a questões burocráticas.

Não existe uma troca de informações. O relacionamento com a Administração de Pessoal é somente quando é necessário solicitar um direito, como férias, ou algum documento, em que se vai ao setor, preenche uma solicitação e se tem um retorno do solicitado. Mas não existe uma troca de informações no dia a dia (E2).

Quanto a este ponto, o Entrevistado 1 enfatiza que:

Além da relação burocrática, eu possuía uma relação de amizade com alguns outros agentes públicos, havendo certa 'liberdade' entre os servidores de perguntar algo relacionado ao seu trabalho seja a um diretor, a um secretário, ou até mesmo ao próprio Prefeito (E1).

Como exposto por Brandão et al. (2009), a gestão por competência dispõe de meios eficientes para otimizar uma gestão organizacional, tornando-se uma ferramenta fundamental. Norteados por essa afirmativa e considerando essa gestão como meio de elaboração de estratégias que propiciam o desenvolvimento do capital humano e institucional, no que se concerne ao conhecimento dos entrevistados acerca do tema em questão, verificou-se que apenas o Entrevistado 2 possui uma melhor compreensão com relação ao que se refere gestão por competências e sua importância no setor público, enquanto os entrevistados 1 e 3, detêm um conhecimento bastante limitado.

Essa gestão é primordial, não sendo possível administrar uma Prefeitura sem projetos, sem ideias, sem comunicação com os funcionários, sem o diálogo na tentativa de melhorar os serviços prestados. Tudo pode ser melhorado, eu trago isso da própria programação, nenhum sistema está pronto, eu posso sempre evoluir e quem vai descobrir isso é o usuário que recebe diretamente $o$ atendimento (E1).

O gestor que trabalhar dentro desse aspecto, o município, ou a entidade que ele esteja dirigindo no momento, seja Estado ou União, só tem a ganhar, porque a gestão por competências está atrelada a pessoas que realmente tem competências para desenvolver suas atividades com um bom desempenho, em que essas pessoas devem ser lembradas e melhor beneficiadas e reconhecidas porque são pessoas que estão gerando produção para o município e para a sociedade, mas infelizmente isso não é possível se ver no dia a dia (E2).

É importante em todos os aspectos. É necessário ter humildade para se trabalhar com as pessoas tanto da zona rural como da zona urbana, tem que atender também a toda a sociedade que procura a nós, funcionários da Prefeitura, assim como outras pessoas de fora que nos procuram para saber informações até mesmo de outras gestões. A qualidade do atendimento é o principal (E3).

Essa limitação torna-se uma preocupação, uma vez que a abordagem por competências pode ser vista como uma alternativa favorável para alcançar resultados efetivos e gerar valor no contexto de trabalho, a fim de que os objetivos sejam alcançados, principalmente, no que se refere ao atendimento do interesse público. 


\section{CONCLUSÕES}

Intencionou-se com este estudo provocar uma reflexão acerca da importância da Gestão por Competências como ferramenta eficiente para as organizações públicas. Assim, baseado na teoria, o planejamento da força de trabalho seria consideravelmente eficaz, se existisse uma maior flexibilidade e efetividade na gestão do conjunto de servidores, como coloca o OCDE (2010). Contudo, está pesquisa teve como propósito identificar a maneira como ocorre a alocação dos assistentes técnicos da Prefeitura Municipal de São Mamede - PB, sendo desenvolvida por meio de um roteiro de entrevista em profundidade.

O contexto explorado foi a percepção dos servidores públicos desta categoria acerca de alguns pontos que fundamentaram esta pesquisa, como conhecimentos, habilidades e atitudes, o entendimento sobre as atribuições que Ihes competem, a consciência da participação deles no alcance do objetivo proposto pela Administração Pública, suas qualificações profissionais como meio de potencializar as atividades exercidas, a relação Administração de Pessoal e servidor público, considerando este um fator essencial para a identificação e gerenciamento de competências e a concepção dos entrevistados acerca da Gestão por Competências.

Com relação à definição institucional do cargo de assistente técnico e suas atribuições, é importante destacar que dois sujeitos, um deles com anos expressivos de exercício no departamento de pessoal, não possuem conhecimento acerca do documento existente que traz essas questões estabelecidas. Atrelado a essa concepção, vale aferir sobre a existência de uma possível falha na comunicação interna, inerente à amplitude das dinâmicas de trabalho do setor de recursos humanos, o que pode comprometer o desempenho das atividades, uma vez que é necessário que os servidores públicos municipais conheçam as atribuições características aos cargos ocupados para que, consequentemente, cada um tenha clareza do seu papel no processo de alcance das metas públicas estabelecidas.

Também foi possível perceber, diante da análise dos resultados que foi realizada, que os colaboradores possuem certa dificuldade, variada em diferentes graus, em relação à compreensão do que é a Gestão por Competências e uma limitação a respeito de como as competências que cada um possui pode influenciar no desempenho organizacional.

Ainda nessa perspectiva, vale ressaltar que, a alocação do Entrevistado 2 é pertinente as suas competências técnicas. No que tange ao Entrevistado 1, ao assumir o concurso público, sua designação não foi condizente aos seus conhecimentos técnicos, assim como suas qualificações não se enquadravam com a função exercida inicialmente. Sobre o Entrevistado 3, é possível constatar que sua atuação atual desconsidera sua experiência obtida ao longo dos anos. Hodiernamente, foi possível presumir que os assistentes técnicos do órgão municipal estudado, atendem as exigências pertinentes às atribuições do cargo que ocupam, devido à vasta experiência adquirida por meio dos anos de exercício no serviço público municipal, embora a maneira com a qual os servidores foram alocados, durante todo período de atuação no funcionalismo público, não observava as competências de cada um, uma vez que não existe um método de identificação destas.

Outro ponto fundamental enfatizado é a respeito das qualificações e treinamentos proporcionados 
pelo órgão estudado. Esses mecanismos que auxiliam os colaboradores a potencializar suas competências são fornecidos com certa periodicidade e, de fato os resultados no que concerne à agregação de novos conhecimentos, são satisfatórios.

Todas estas questões identificadas por meio do presente estudo tornam-se um alerta para que a entidade pública estudada passe a considerar a Gestão de Pessoas por Competências como uma ferramenta efetiva de integração e mudança, no sentindo de identificar e gerir profissionais, o que pode garantir um retorno positivo ao órgão como verificar oportunidades de melhorias a serem realizadas e pontos de excelência, suprir possíveis lacunas existentes e agregar valor ao capital humano e institucional.

No que se refere as limitações do estudo, deve-se salientar que a investigação ficou restrita a um único município, portanto, suas conclusões compreendem apenas o referido contexto, o que nos permite perceber a necessidade de continuidade da discussão e do aprofundamento sobre o tema, a fim de que a Gestão por Competências na esfera pública torne-se uma realidade, auxiliando a administração a alcançar sua missão no contexto em que está inserida.

Portanto, sugere-se para possíveis pesquisas futuras a realização de trabalhos que analise quais os principais desafios da gestão pública em aplicar a Gestão por Competências e qual o nível de influência desses desafios ordenados de acordo com os diferentes tipos de setores que compõem a esfera de um governo.

\section{REFERÊNCIAS}

AMARAL, H. K.. Desenvolvimento de competências de servidores na administração pública brasileira. Revista do Serviço Público, Brasília, n.57, v.4, p.549-563, 2006.

BRANDÃO, H. P.; GUIMARAES, T. A.. Gestão de competências e gestão de desempenho: tecnologias distintas ou instrumentos de um mesmo construto?. Revista de Administração de Empresas, São Paulo, v.41, n.1, p.8-15, 2001.

BRANCHIER, A. S.; TESOLIN, J. D. D.. Direito e legislação aplicada. 3 ed. Curitiba: Ibpex, 2007.

BRASIL. Constituição da República Federativa do Brasil 1988. Brasília: DOU, 1988.

BRESSER-PEREIRA, L. C.. A restrição democrática na reforma da gestão pública. 2002.

CAPUANO, E. A.. Gestão por competências no setor público: experiências de países avançados e lições para o Brasil. Revista do Serviço Público, Brasília, v.66, n.3, p.371-394, 2015.

FLICK, U.. Introdução à pesquisa qualitativa. 3 ed. Porto Alegre: Artmed, 2009.

GEMELLI, I. M. P.; FILIPPIM, E. S.. Gestão de pessoas na administração pública: o desafio dos municípios. Revista de Administração, Contabilidade e Economia, v.9, n.1-2, p.153180, 2010.
IBGE. Instituto Brasileiro de Geografia e Estatística. Censo Demográfico 2018: São Mamede. IBGE, 2018.

LE BOTERF, G.. Desenvolvendo a competência dos profissionais. 3 ed. Porto Alegre: Artmed, 2003.

OCDE. Organização para Cooperação e Desenvolvimento Econômico. Avaliação da gestão de recursos humanos no governo: relatório da OCDE: Brasil, Governo Federal. Paris: OECD Publishing, 2010.

PERDIGÃO, D. M.; HERLINGER, M.; WHITE, O. M.. Teoria e prática da pesquisa aplicada. Rio de Janeiro: Elsevier, 2012.

SELLTIZ, C.; JAHODA, M.; DEUTSCH, M.; COOK, S. W.. Métodos de pesquisa nas relações sociais. São Paulo: Herder, 1972.

SEVERINO, A. J.. Metodologia do trabalho científico. São Paulo: Cortez, 2018.

SMOLSKI, F. M. S.; DALCIN, D.; VISENTINI, M. S.; BAMBERG, J.. Análise do perfil da produção científica da Revista de Administração Pública (RAP) no período 2003-16. Revista de Administração Pública, v.51, n.6, p.1139-1163, 2017. DOI: http://doi.org/10.1590/0034-761220170046

ZANELLA, L. C. H.. Metodologia de estudo e de pesquisa em administração. Florianópolis: Departamento de Ciências da Administração. UFSC, 2012.

A CBPC - Companhia Brasileira de Produção Científica (CNPJ: 11.221.422/0001-03) detém os direitos materiais desta publicação. Os direitos referem-se à publicação do trabalho em qualquer parte do mundo, incluindo os direitos às renovações, expansões e disseminações da contribuição, bem como outros direitos subsidiários. Todos os trabalhos publicados eletronicamente poderão posteriormente ser publicados em coletâneas impressas sob coordenação da Sustenere Publishing, da Companhia Brasileira de Produção Científica e seus parceiros autorizados. Os (as) autores (as) preservam os direitos autorais, mas não têm permissão para a publicação da contribuição em outro meio, impresso ou digital, em português ou em tradução. 